Research Paper

\title{
Interleukin-11 Promotes the Progress of Gastric Carcinoma via Abnormally Expressed Versican
}

\author{
Zhenwei Zhang"\#, Jianpeng Zhang1\#, Lei Miao², Ke Liu³, Shengsheng Yang1', Chuanyong Pan¹, Binghua \\ $\mathrm{Jiao}^{1}{ }^{\otimes}$
}

1. Department of Biochemistry and Molecular Biology, Second Military Medical University, Shanghai 200433, China;

2. Department of Pharmacology, Zhejiang Chinese Medical University, Hangzhou 310053, China;

3. Department of Medical Oncology, Changzheng Hospital, Shanghai, 200070, China.

\# These authors contributed equally to this paper.

Corresponding author: Prof. Binghua Jiao, Department of Biochemistry and Molecular Biology, Second Military Medical University, No.800 Xiangyin Road, Shanghai, 200433, China. Tel: +86-21-81870970-8001, Fax: +86-21-65334333, E-mail: jiaobh@live.cn.

(C) Ivyspring International Publisher. This is an open-access article distributed under the terms of the Creative Commons License (http:/ / creativecommons.org/ licenses/by-nc-nd/3.0/). Reproduction is permitted for personal, noncommercial use, provided that the article is in whole, unmodified, and properly cited.

Received: 2011.10.07; Accepted: 2012.02.18; Published: 2012.02.23

\begin{abstract}
Versican, a ubiquitous component of the extracellular matrix (ECM), accumulates both in tumor stroma and cancer cells and is highly regulated by various cytokines. The aberrant expression of versican and its isoforms is known to modulate cell proliferation, differentiation, and migration, all of which are features of the invasion and metastasis of cancer; versican is also known to favour the homeostasis of the ECM. Interleukin-II (IL-II) is an important cytokine that exhibits a wide variety of biological effects in gastric cancer development. Here, we analysed the expression of versican isoforms and found that the major isoforms expressed by both gastric carcinoma tissue and gastric cell lines were $\mathrm{V} 0$ and $\mathrm{VI}$, and $\mathrm{VI}$ was significantly higher in gastric carcinoma tissue. The treatment of the gastric cell lines AGS and MKN45 with rhIL-I I resulted in a significant increase in the expression of $\mathrm{VO}$ and $\mathrm{VI}$. Exogenous IL- I I increased migration in AGS and MKN45 cells, whereas these effects were reversed when the expression of V0 and VI were abolished by siRNA targeting versican V0/VI. Collectively, these findings suggest that the abnormally expressed versican and its isoforms participate, at least in part, in the progress of gastric carcinoma triggered by IL-I I .
\end{abstract}

Key words: Versican; IL-11; gastric carcinoma; migration.

\section{Introduction}

Gastric carcinoma, the fourth most common malignancy and the second most frequent cause of cancer death, is the result of accumulated genomic damage, affecting cellular functions essential for cancer development $[1,2]$. A considerable body of evidence suggests that the tumour environment is one of the major factors that determine the behaviour of malignant cells. Additionally, the tumour cell invasion and subsequent metastasis, which are complex and mul- ti-step mechanisms are critical steps in the progression of malignant tumours, including gastric carcinoma.

The extracellular matrix (ECM), which is mainly composed of proteoglycans, glycoproteins and collagens, is a complex structural entity surrounding and supporting cells within tissues and playing many physiological and pathological roles. The ECM maintains tissue integrity and homeostasis and provides a 
reservoir of cytokines and growth factors. Modification of the ECM composition through a large array of molecules and cell-cell and cell-matrix interactions may be crucial for tumour initiation and progression[3].

Versican is an ECM molecule, and it accumulates both in tumour stroma and cancer cells[4]. It is known to modulate cell proliferation, differentiation, adhesion, and migration, all of which are features of the invasion and metastasis of cancer, and versican is known to favour the homeostasis of $\operatorname{ECM}[4,5]$. Thus, this molecule may play a wide range of roles in the invasion and metastasis of tumour cells. Structurally, versican consists of $\mathrm{N}$-and $\mathrm{C}$-terminal globular domains and two chondroitin sulphate domains (CS- $\alpha$ and CS- $\beta$ ), which are encoded by differential splicing exons. Alternative splicing generates at least four isoforms of versican, known as V0, V1, V2, and V3[6]. V0 contains both CS- $\alpha$ and CS- $\beta$; V1 and V2 possess only CS- $\beta$ and CS- $\alpha$, respectively; and V3 has only the globular domains. The versican V0 and V1 isoforms are mainly expressed in the late stage of embryonic development[7], whereas V2 is one of the main constituents of the mature neural ECM[8]. By virtue of its differing domains and motifs, versican binds to a number of molecules in the ECM such as hyaluronan, type I collagen, tenascin-R, fibulin-1, and -2, fibrillin-1, fibronectin, P- and L-selectins, and chemokines[9-14], and interacts with the cell surface proteins epidermal growth factor receptor (EGFR), CD44, integrin $\beta 1$, and P-selectin glycoprotein ligand-1[15, 16]. As a large member of the lectican family of proteoglycans, versican also affects the cytokeleton rearrangement and assembly[17]. Moreover, the versican conditional knock-out mice exhibit distorted digits and delayed cartilage development[18].

The literature spanning the last decade has ascertained a significant involvement of versican in tumour progression. An increased concentration of versican may be obligatory for angiogenesis and metastasis in tumours[19]. A number of reports within the last few years have identified a significant involvement of versican in gastric carcinomas: one report provided evidence that the level of versican in gastrointestinal stromal tumours was significantly higher, and the highly expressed protein was correlated with poor disease-free survival[20]. From an analysis of $\Delta$-disaccharides, it was observed that versican expression was significantly increased by approximately 3-fold in human gastric carcinomas[21]. Naohide Oue et al. determined that versican was expressed at much lower levels in tumour-associated stromal areas of atomic-bomb-exposed patients than in non-exposed patients[1]. Additionally, the genetic variants $\mathrm{A} 1826 \mathrm{H}$ and $\mathrm{D} 2937 \mathrm{Y}$ in the GAG- $\beta$ domain of versican could influence a patient's susceptibility to intestinal-type gastric cancer[22].

Studies to date have identified a number of cytokines or growth factors such as transforming growth factors $\beta 2$ and $\beta 3$ (TGF- $\beta 2$ and TGF- $\beta 3$ ), basic fibroblast growth factor (bFGF), platelet-derived growth factor BB (PDGF-BB), and interleukin-1 $\beta$ (IL-1 $\beta$ ), that regulate the synthesis of versican[23-25], and among these factors, IL- $1 \beta$ down-regulates the expression of versican in arterial smooth muscle cells[25]. However, because the related data remain limited and fragmentary, it is nebulous to determine which factors regulate the synthesis of the ECM components in gastric carcinoma.

Interleukin-11 (IL-11), a cytokine that exhibits a wide variety of biological effects in neutrophils as well as in the haematopoietic and immune systems, is also involved in gastric cancer development[26]. The majority of gastric carcinomas express IL-11 and its receptor-a[27]. Sharing gp130 as a signalling mechanism with several cytokines and growth factors, including IL-6, oncostatin M, and leukaemia inhibitory factor (LIF), IL-11 promotes the migration of gastric cancer cells by the activation of the phosphatidylinositol-3 kinase pathway[27, 28].

IL-11 and versican have been independently reported to be upregulated in gastric carcinomas[20, 21, 29], suggesting a possible link between the upregulation of these two species. Additionally, no study has been conducted to determine whether IL-11 has specific effects on proteoglycan, specifically versican synthesis by gastric cancer cells. In this study, we investigated the differential expression of versican and its isoforms in gastric carcinoma tissue and cells, and analyzed whether treatment with exogenous IL-11 could regulate versican synthesis in the gastric cell lines AGS and MKN45. Furthermore, we explored the effects of IL-11 on the migration and proliferation of AGS and MKN45 cells, and analyzed whether these effects were reversed when the expression of $\mathrm{V} 0$ and V1 were abolished by siRNA targeting versican V0/V1.

\section{Materials and methods}

\section{Clinical materials}

Fourteen freshly frozen tissue samples and the corresponding normal areas adjacent to where the tumour specimens $(\geq 5 \mathrm{~cm})$ were taken from the patients (ten men, four women; aged from 47-79 years, mean 64) with gastric cancer were collected. All of the patients who underwent curative resection for primary gastric adenocarcinomas (referred to "gastric 
carcinoma" in this report) were operated on at Shanghai Changhai Hospital. All of the tissue specimens were obtained for the present study with the patient's informed consent. The collection of these tissue samples was undertaken with the approval of the Changhai Hospital Institutional Review Board. Each tissue fragment was divided into two parts. One portion was processed for quantitative real-time PCR (Q-RT-PCR) analyses, the second portion for Western blot analyses, freezing them in liquid nitrogen.

\section{Cell culture}

The following human gastric carcinoma cell lines were used: AGS was purchased from American Type Culture Collection; MKN45, SH-10-TC, and HGC-27 were obtained from Riken Bio Resource Centre; and MKN28, SGC-7901, MGc80-3, BGC-823, and GES were provided by the Institute of Biochemistry and Cell Biology of the Chinese Academy of Science. All of the cells were maintained in RPMI 1640 (Biowest) medium supplemented with 10\% FBS (Biowest), 100 $\mathrm{U} / \mathrm{ml}$ penicillin, $100 \mu \mathrm{g} / \mathrm{ml}$ streptomycin sulphate, and $1 \mathrm{mM}$ sodium pyruvate at $37^{\circ} \mathrm{C}$ in $5 \% \mathrm{CO}_{2}$. The cells were passaged with trypsin-EDTA $(0.05 \%$ trypsin and $0.53 \mathrm{mM}$ tetrasodium EDTA).

To elucidate the effect of exogenous IL-11 on the regulation of versican isoforms, we performed treatment assays with different concentrations of rhIL- 11 . The gastric carcinoma cells were seeded at an equal density in cell culture flasks containing growth medium as described above. After $24 \mathrm{~h}$, triplicate samples of subconfluent cells were treated with four different concentrations $(0,20,50,100$ and $200 \mathrm{ng} / \mathrm{ml})$ of activated rhIL-11 protein (R\&D Systems, Minneapolis, MN, USA) and incubated for $24 \mathrm{~h}$. The cells were harvested to prepare mRNA and protein as described below. In the time-point assays, the cells were treated with $100 \mathrm{ng} / \mathrm{ml}$ of rhIL-11 and harvested at three different time points: hours 24,48 and 72.

\section{RT-PCR and Q-RT-PCR}

The total RNA was isolated from frozen tissues, and cells were treated with the TRIzol (Takara, Dalian, China) method or left untreated according to the manufacturer's protocol. The RNA quality (A260/A280 ratio) and quantity were determined using a standard spectrophotometer. One microgram of total RNA was used for cDNA synthesis using the RevertAidtm First Strand cDNA Synthesis Kit \#1622 (Fermentas, Vilnius, Lithuania) according to the manufacturer's instructions. Appropriate forward and reverse primers to detect transcripts of interest were used in the reverse transcriptase polymerase chain reactions (RT-PCRs) for cDNA amplification.
The primer sequences for GAPDH were 5'-CAAGGTCATCCATGACAACTTTG-3' (forward) and 5'-GTCCACCACCCTGTTGCTGTAG-3'(reverse). The primer sequences for the versican $\mathrm{V} 0, \mathrm{~V} 1, \mathrm{~V} 2$, and V3 isoforms were previously described[9]: V0: 5'-GACCTCAGGCGCTTTC-3'(forward) and 5'-CAGTGGTAACGAGATGCTTC-3'(reverse); V1: $5^{\prime}$-GCGCCACCCTGTGAC-3'(forward) and 5'CAGTGGTAACGAGATGCTTC-3'(reverse); V2: 5'-GACCTCAGGCGCTTTC-3' (forward) and 5'-TAGCACTGCCCTTGGA-3'(reverse); V3: 5'-TGAGAACCCTGTATCGTTTTGAGA-3'(forward) and 5'-CGTTAAGGCACGGGTTCATT-3'(reverse). The PCR conditions used for the amplification were as follows: $94^{\circ} \mathrm{C}$ for $10 \mathrm{~min}$, then 40 cycles of $94^{\circ} \mathrm{C}$ for 30 $\mathrm{s}, 55-58^{\circ} \mathrm{C}$ for $30 \mathrm{~s}$, and $72^{\circ} \mathrm{C}$ for $45 \mathrm{~s}$, followed by $72{ }^{\circ} \mathrm{C}$ for $10 \mathrm{~min}$. The RT-PCR products were analysed on a $1 \%$ agarose gel and visualised with ethidium bromide staining. The GAPDH gene was used as a positive control to assess the cDNA quality.

Q-RT-PCR was conducted using a 7300 Real-time PCR System (Applied Biosystems). For the semi-quantification of the genes of interest, we utilised the QPK-201 SYBR Green master mix (Toyobo, Osaka, Japan). The target cDNA-specific primers of versican isoforms as described above were established. Standard curves were plotted for each optimised assay, each of which produced a linear plot of the threshold cycle $(\mathrm{Ct})$ against log (dilution). The amount of each target was quantified based on the concentration obtained from the standard curve and was presented in arbitrary units. The quantity of each target was normalised against the quantity of GAPDH.

\section{siRNAs preparation and Transfection}

The siRNAs to human versican V0/V1 were chemically synthesised by Shanghai GenePharma Co., Ltd.. The siRNA sequences for the indicated genes were designed as follows: siRNA-V0/V1: 5'-GAGGCUGGAACUGUUAUUATT-3' (forward) and 5'-UAAUAACAGUUCCAGCCUCTT-3' (reverse). The negative control dsRNA were as follows: 5'-UUCUCCGAACGUGUCACGUTT-3' (forward) and 5'-ACGUGACACGUUCGGAGAATT-3' (reverse).

According to the manufacturer's specifications, the transfection of siRNA-V0/V1 was achieved with Lipo2000 (Invitrogen, Gaithersburg, MD) in 6-well plates. In brief, one day before transfection, $2.0 \times 10^{5}$ cells in $2 \mathrm{ml}$ of growth medium without antibiotics were grown such that they would be $30-50 \%$ confluent at the time of transfection. The Lipo2000 diluted in Opti-MEM I Reduced Serum medium (Gibco) with- 
out serum was used to supplement the dsRNA mixture, and the formulation lasted for $25 \mathrm{~min}$. Next, $6 \mu \mathrm{l}$ of $20 \mu \mathrm{M}$ dsRNA formulated with $8 \mu \mathrm{L}$ Lipo2000 was added to a final volume of $2 \mathrm{ml}$ Opti-MEM I Reduced Serum medium. Cells were incubated at $37^{\circ} \mathrm{C}$ in a $\mathrm{CO}_{2}$ incubator for 24-48 h. The medium was changed after $6 \mathrm{~h}$.

\section{Western blot analysis}

Whole-cell lysates were prepared from human tissue specimens and treated cells. The insoluble tissue debris was removed by centrifugation at $13,000 \times \mathrm{g}$ at $4^{\circ} \mathrm{C}$ for $15 \mathrm{~min}$. The supernatant was collected, and the protein concentration was quantified using a protein assay reagent (BCA, Beyotime, Shanghai). The proteins were separated by SDS-PAGE, transferred to a nitrocellulose membrane and incubated with the polyclonal antibody anti-Versican V0/V1 Neo (Sigma, St. Louis, MO, USA), polyclonal antibody anti-human IL-11 (Peprotech, NJ, USA) at $4^{\circ} \mathrm{C}$ overnight. The immunocomplexes were visualised using a horseradish peroxidase-conjugated antibody followed by a chemoluminescence reagent (Millipore, Billerica, MA, USA) and detected on photographic film.

\section{Cell proliferation assay}

The AGS and MKN45 cells were treated with rhIL-11 $(100 \mathrm{ng} / \mathrm{ml})$ at various time points $(0,24,36$, 48,60 , and $72 \mathrm{~h}$ ). And, after treated with siRNA for 24 hours, the proliferation of AGS cells was also analysed at two time points (24 and $48 \mathrm{~h}$ ). The cell growth was determined by Cell Counting Kit- 8 assay (R\&S Biotechnology, Shanghai) according to the manufacture's protocol. Experiments were performed in triplicate.

\section{Scratch migration assay}

Scratch migration assays were performed as described previously[30, 31]. Briefly, $1.8 \times 10^{6}$ cells per well were seeded in 6-well plates and incubated with growth medium as described above. After allowing the cells to adhere to the plates and reach $95 \%$ confluence, the nearly confluent cell monolayers were scratched using yellow sterile pipette tips. Cells were then washed with PBS to remove the cellular debris, and the wounded monolayers were incubated in 5\% FBS medium containing rhIL-11 $(100 \mathrm{ng} / \mathrm{ml})$ and bovine serum albumin (BSA, $100 \mathrm{ng} / \mathrm{ml}$ ) as a control. The migration of the cells into the scratch was observed by a blinded investigator and photographed at time points of $0 \mathrm{~h}, 12 \mathrm{~h}, 24 \mathrm{~h}, 36 \mathrm{~h}$ and $48 \mathrm{~h}$. The distance migrated by the cells was quantitated and compared with that of the untreated control using statistical analyses. The experiments were repeated in duplicate wells at least three times.

\section{Transwell assay}

Transwell assays were performed using polycarbonate transwell filters (Corning, $8 \mu \mathrm{m}$ ) placed over the bottom chambers that were filled with culture medium containing $20 \%$ FBS. The cells suspended in RPMI1640 medium containing 1\% FBS were added to the upper chamber containing rhIL-11 $(100 \mathrm{ng} / \mathrm{ml})$ or BSA $(100 \mathrm{ng} / \mathrm{ml})$ as a control. A sample of $1.75 \times 10^{5}$ cells that was treated for $24 \mathrm{~h}$ with a siRNA-V0/V1/Lipo2000 mixture and a NC/Lipo2000 mixture was seeded into the upper well. After $48 \mathrm{~h}$, cells on the upper surface of the well were removed, and cells on the lower surface were fixed in cold methanol and stained with $0.4 \%$ crystal violet. For each experiment, the number of transmigrated cells in five random fields on the underside of the filter was counted and photographed, and three independent filters were analysed.

\section{Statistic analysis}

Data were expressed as the mean $\pm \mathrm{SD}$. The statistical analyses were performed using a Student's $t$-test as indicated in the figure legends. A $p$ value less than 0.05 was considered to be statistically significant.

\section{Results}

\section{Identification of differential versican expres- sion in gastric carcinoma tissue and cells}

Recently, there has been evidence that the expression level of versican in gastrointestinal stromal tumours is significantly higher, and the highly expressed protein is correlated with poor disease-free survival[20]. In our study, Q-RT-PCR was performed on gastric samples to screen for the differential expression of the versican isoforms. V1 exhibited a significantly higher expression in the gastric carcinoma tissue than the other isoforms did (Fig. 1A; P<0.05). In the RT-PCR results, the isoforms exhibited profiles nearly identical to those obtained by Q-RT-PCR (Fig. 1B). To further compare the differential expression of versican in the gastric tissue, all 28 gastric samples (14 in situ carcinomas and 14 corresponding to adjacent normal gastric mucosa) were analysed by Western blot targeting versican V0 and V1. The results showed that V0/V1 revealed a significantly higher expression in gastric carcinoma tissue than in adjacent normal tissue (Fig. 1C; $\mathrm{P}<0.05$ ). Additionally, the expression profiles of versican isoforms were examined in nine human gastric carcinoma cell lines by means of RT-PCR at the mRNA level, using GAPDH as the control gene. 


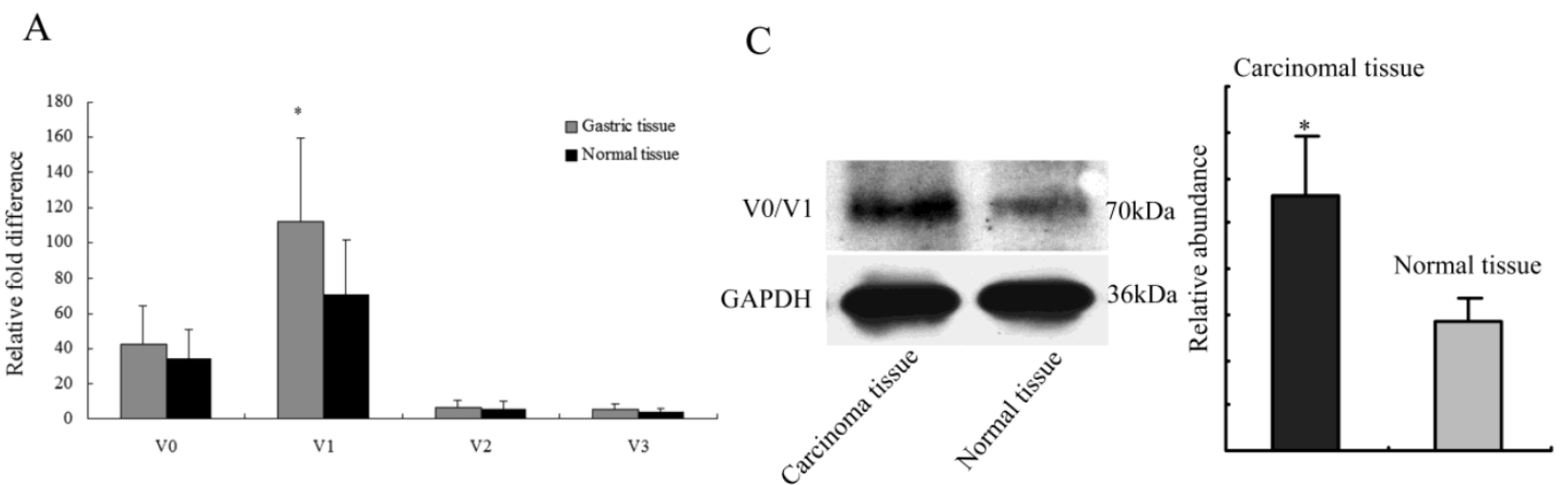

B

$\mathrm{D}$
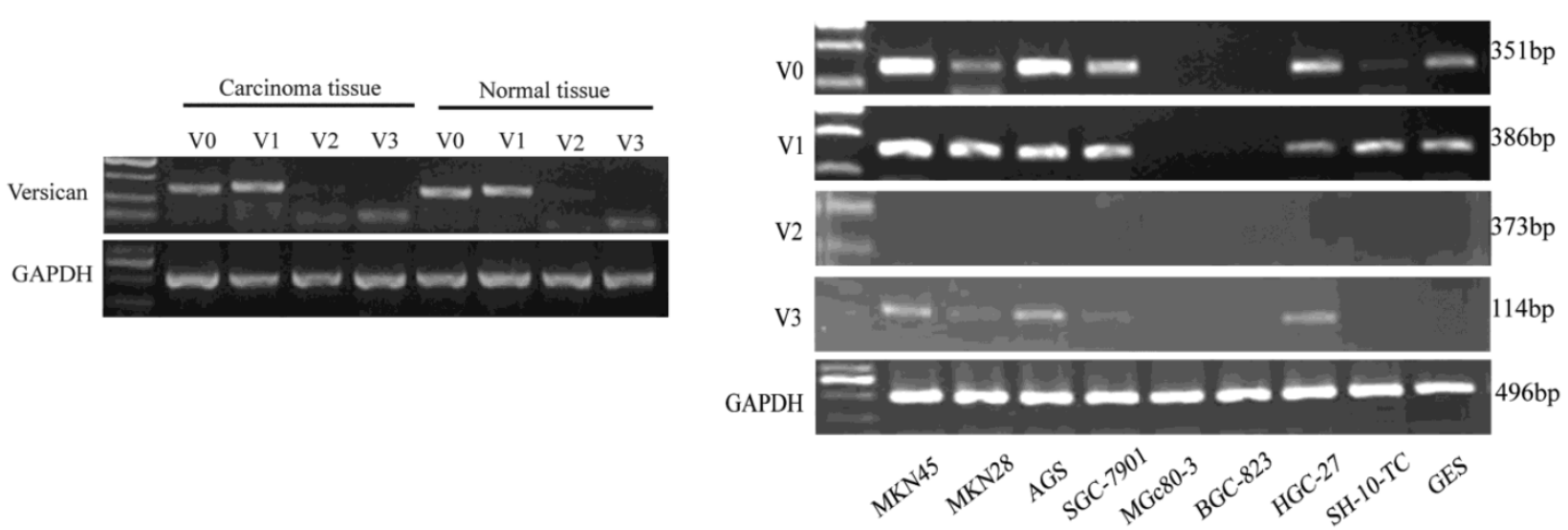

Fig I. Differential expression of versican and its isoforms. (A) Q-RT-PCR analysis of the expression of the versican mRNA isoforms in the gastric carcinoma tissue and the adjacent normal tissue samples. Four isoforms were analysed in the gastric carcinoma tissue and adjacent normal tissue. VI revealed a significantly higher expression ( $* \mathrm{P}<0.05)$. (B) RT-PCR analysis of the versican isoforms. The results agree well with those of the Q-RT-PCR analysis shown in Fig. I A. (C) The expression of versican V0/VI was determined by Western blot. Versican was significantly up-regulated in gastric carcinoma tissue than in adjacent normal tissue (*P<0.05). GAPDH was used as the loading control. (D) Versican isoform variants in human gastric carcinoma cell lines. V0 and VI were found to be expressed in most gastric cells. GAPDH was used to adjust for cDNA quantity.

The experiments showed that most gastric carcinoma cell lines expressed the V0 and V1 isoforms in different amounts but with the same expression pattern. V3 was expressed only slightly in some cell lines, whereas V2 was not found in any cell lines (Fig. 1D).

These findings, which are consistent with the previous results, suggested that the expression of versican was significantly higher in gastric carcinoma tissue in comparison with the adjacent normal tissue, and V0 and V1 were the most highly expressed isoforms in these samples as well as some gastric carcinoma cell lines.

\section{Both VO and VI exhibit variant expression in cell culture after treatment with exogenous IL-I I}

It has been shown that cytokine IL-11 can increase the proliferation and metastasis of gastric epi- thelial cells and promote inflammation-associated gastric tumourigenesis[29, 32]. Versican, which is regulated by many cytokines, is a TLR2 agonist and metastasis-enhancing factor[33]. These observations suggest that a possible link between IL-11 and versican exists in gastric cells. Here we mainly studied the effect of rhIL11 on the versican V0 and V1 isoforms because they were the most highly expressed isoforms in the gastric tumours and cell lines. After treatment of AGS cells with four different concentrations $(10,50$, 100 , and $200 \mathrm{ng} / \mathrm{ml}$ ) of rhIL-11, V0 and V1 both showed a significant increase in a concentration-dependent manner (Fig. 2A; $\mathrm{P}<0.05, \mathrm{P}<0.01$ ). Similarly, in MKN45 cells treated with $100 \mathrm{ng} / \mathrm{ml}$ of rhIL-11, the expression of V0 and V1 reached a peak of 2.6-fold and 2.3-fold, respectively, and then decreased (Fig. 2A; $\mathrm{P}<0.05, \mathrm{P}<0.01$ ). Using Western blot, it was 
confirmed that the expression levels of versican V0/V1 in both cells, which treated with four different concentrations of rhIL-11, kept a line with the Q-RT-PCR results (Fig. 2A). To investigate the time-dependent regulation, three different time points (hours 24, 48 and 72) were used. Both V0 and V1 were upregulated in the two cell lines in a time-dependent

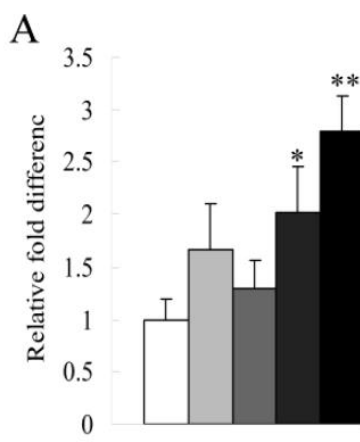

$\mathrm{V} 0$
AGS

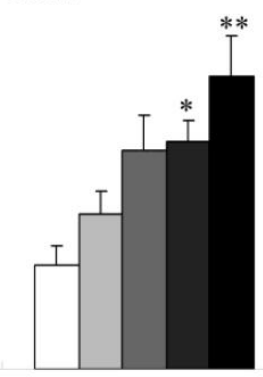

V1 manner (Fig. 2B; $\mathrm{P}<0.05, \mathrm{P}<0.01$ ). Moreover, the western blot also showed a time-dependent upregulation in both cells, which is consistent with results from the Q-RT-PCR analyses (Fig. 2B). Collectively, these results suggested that IL-11 could regulate versican synthesis through the increase of V0 and V1 transcripts in both the AGS and MKN45 cell lines.

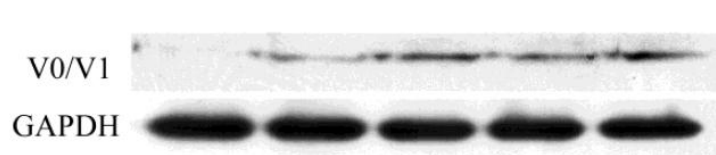

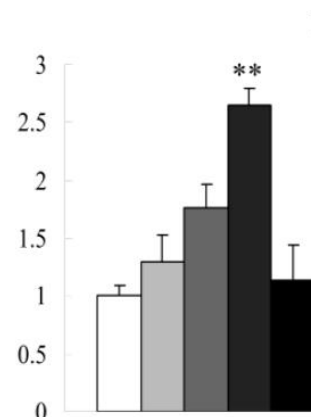

V0
MKN45

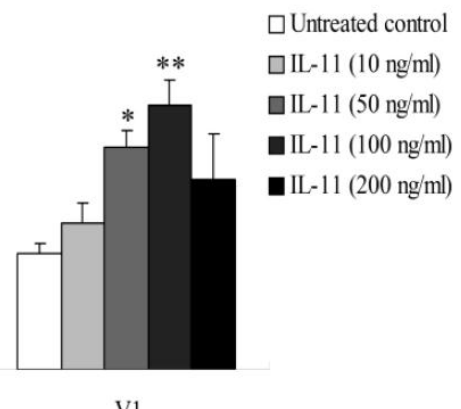

$70 \mathrm{kDa}$

$36 \mathrm{kDa}$

B

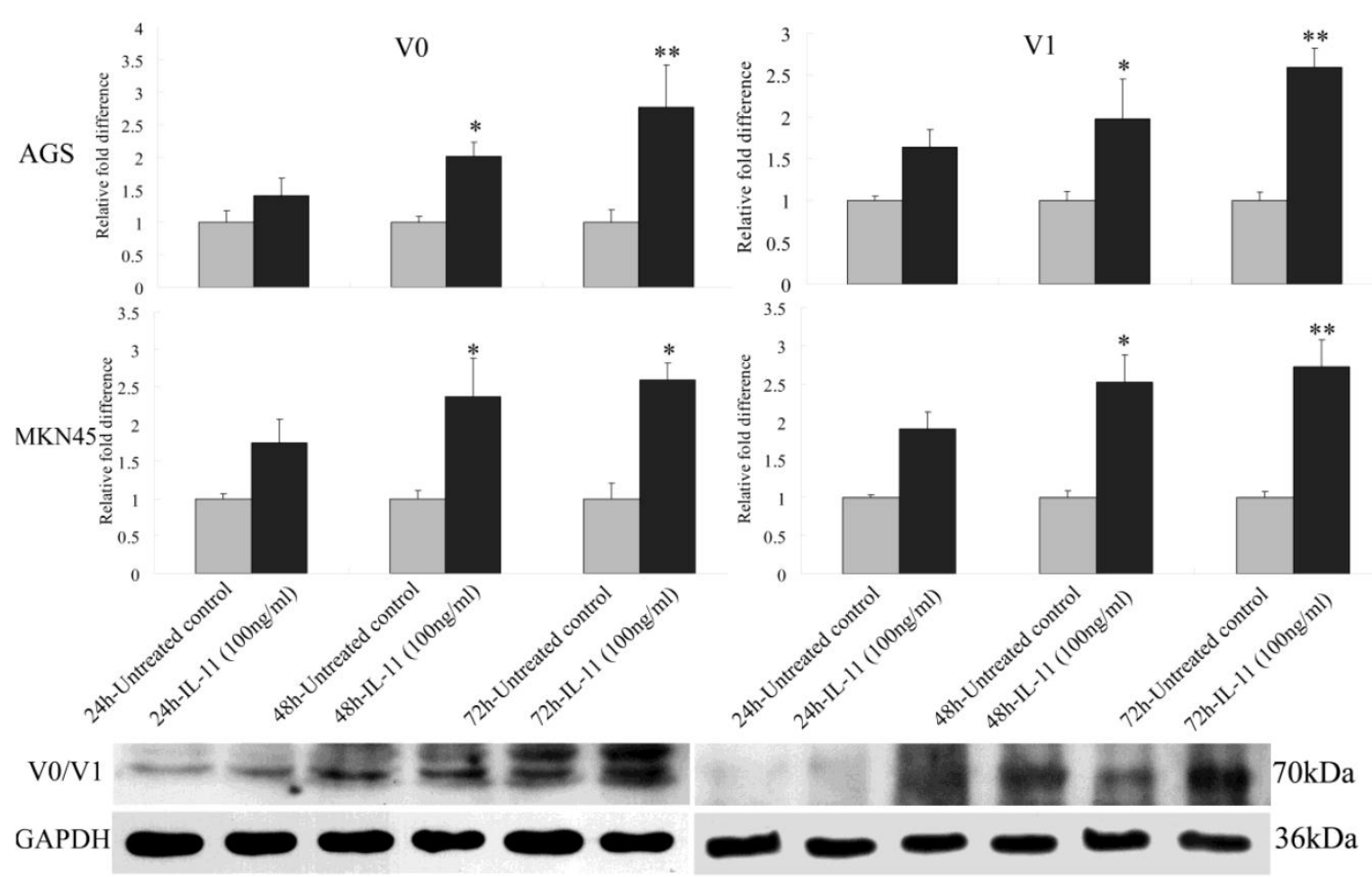

Fig 2. Effects of exogenous IL-II on the expression of the versican V0 and VI isoforms in AGS and MKN45 cells. (A) Four different concentrations $(10,50,100$, and $200 \mathrm{ng} / \mathrm{ml})$ of rhlL-I I were added to AGS and MKN45 cells. In AGS cells, V0 and VI were both upregulated in a concentration-dependent manner. However, in MKN45 cells treated with $100 \mathrm{ng} / \mathrm{ml}$ of rhIL-II, V0 and VI reached peak expression levels of 2.6 -fold and 2.3-fold, respectively $\left({ }^{*} \mathrm{P}<0.05\right.$, $\left.{ }^{* * P}<0.0 \mathrm{I}\right)$. (B) After treatment of AGS and MKN45 cells with rhIL-II (I00 $\mathrm{ng} / \mathrm{ml}$ ) at three different time points (hours 24,48 and 72 ), $\mathrm{V} 0$ and $\mathrm{VI}$ were both upregulated in a time-dependent manner $(* \mathrm{P}<0.05$, $* * \mathrm{P}<0.0 \mathrm{I})$. The quantity of each target was normalised against the quantity of GAPDH. Mean values of the control group were set to a value of $I . n=3$. Results are given as the mean \pm SD. 


\section{Exogenous IL- I I increases migration and pro- liferation in gatric carcinoma cell lines}

To determine if exogenous IL-11 has an effect on gastric carcinoma cells, a transwell assay was performed to assess the migration of AGS cells. In the absence or presence of rhIL-11 (100 ng/ml), AGS cells showed differential migration efficiency. Exposure to rhIL-11 induced the migration rate of AGS cells in spheroid assays more significantly than the untreated control and BSA (Fig. 3A; Fig. 3B; P<0.01) did. In CCK-8 proliferation assay, both cell lines which were treated with rhIL-11 (100 ng/ml) didn't show significantly proliferation until 60 hours (Fig. 3C;P<0.05, $\mathrm{P}<0.01)$. A scratch migration assay was also used to validate the effects of rhIL-11 on AGS and MKN45 cells migration. The migration rate was quantitatively assessed at different time points $(0,12,24,36$ and 48 h). By $36 \mathrm{~h}$, there was an apparent difference in both cells, as shown in Fig. 3D. Similarly, the cells treated with rhIL-11 (100 ng/ml) migrated into the wound with a significantly decreased distance between the edges as compared to the untreated control (Fig. 3D).
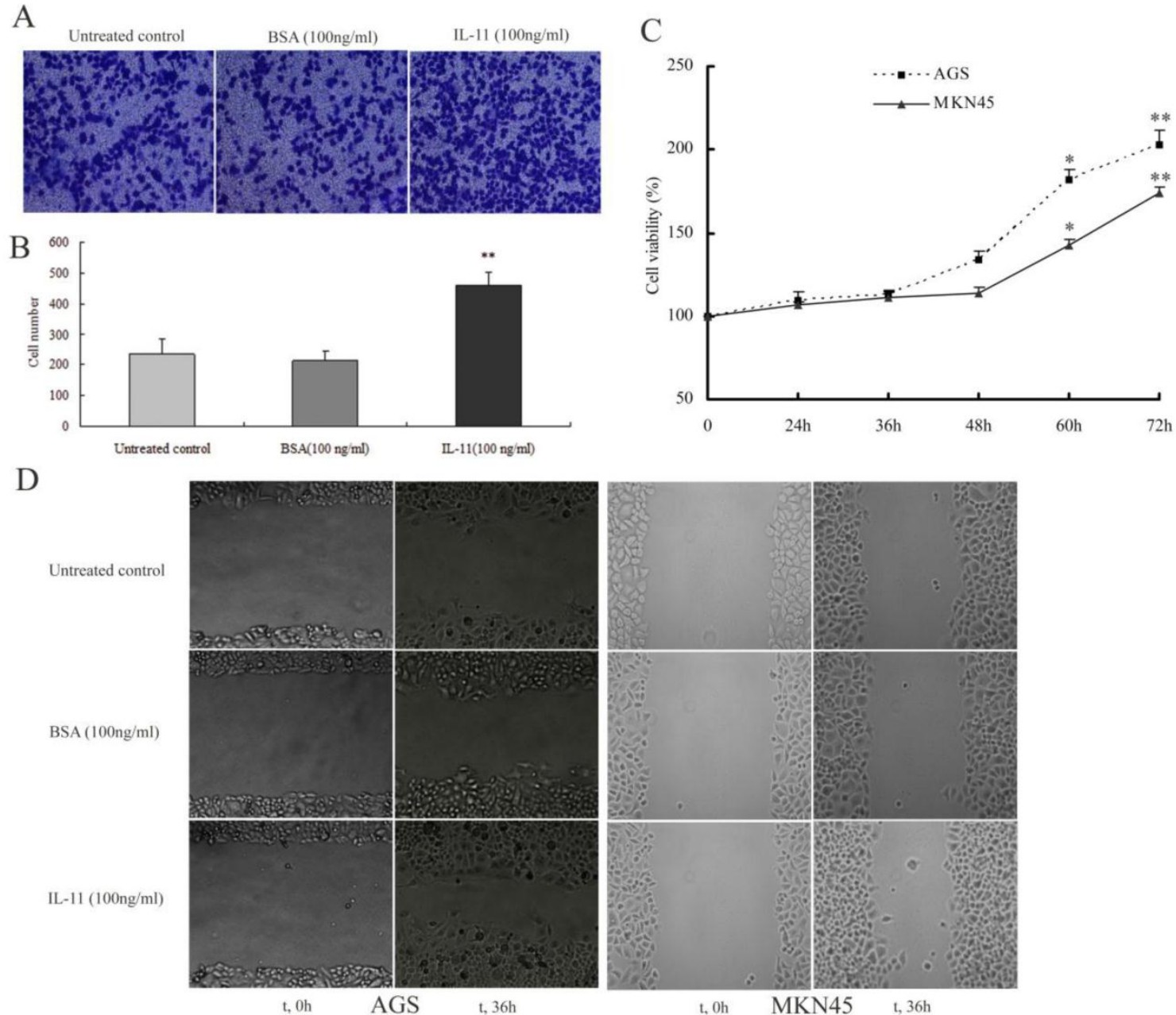

Fig 3. Effect of exogenous IL-II on the migration and proliferation of gatric carcinoma cell lines. (A) The directed migratory capacities of AGS cells treated with rhIL-I I were evaluated using a Transwell migration study. Sample images showing the pro-migratory effect of IL-I I on AGS cells after staining the transmigrated cells with crystal violet (magnification, $\times 100$ ). Exogenous IL-II induced migration more significantly than the untreated control and BSA did. (B) Graphs indicate the average number of cells from five random high-power fields in the indicated groups. Data are presented as mean \pm SD based on three independent experiments $(* * P<0.0 \mathrm{I})$. (C) Proliferative effects of rhIL-I I in gatric carcinoma cell lines (AGS and MKN45 cells) were measured by CCK-8 assay. Both cell lines exhibited significantly growth until 60 hours $\left(* P<0.05\right.$, $\left.{ }^{*} P<0.01\right)$. (D) A scratch migration assay was used to assess the migration of AGS and MKN45 cells that were treated with rhlL-II $(100 \mathrm{ng} / \mathrm{ml})$. The migration rate was quantified by measuring the distance between the edges of the scratch at $\mathrm{t}=0$ relative to $\mathrm{t}=36 \mathrm{~h}$. After incubation, the cells can be seen migrating into the wound with a decreased distance between the edges. 


\section{Abnormally expressed versican participates in gastric carcinoma progression mediated by exogenous IL-I I}

Because versican and IL-11 had the same pro-migratory characteristics in gastric carcinoma cells and because the versican isoforms V0 and V1 were upregulated by IL-11, it was of high interest to assess whether versican participates in gastric carcinoma progression mediated by IL-11. To address this question, we performed transwell assays on the AGS cells transfected with the inhibitory siRNA-versican or the corresponding NC siRNA. After transfection with siRNA for $24 \mathrm{~h}$, the cells were treated with IL-11 $(100 \mathrm{ng} / \mathrm{ml})$ or BSA $(100 \mathrm{ng} / \mathrm{ml})$ in parallel in the two assays.
At the molecular level, V0 and V1 gene expression were significantly decreased, which was verified by realtime PCR (Fig. 4A). In parallel, a quantitative evaluation of the inhibition of versican V0/V1 proteins levels in AGS cells was analysed by a Western blot analysis (Fig. 4B). At the gene level, the results were consistent with those at the protein level and revealed that siRNA-versican inhibits versican expression markedly, but the NC siRNAs do not result in inhibition. And under the same condition, the expression of endogenous IL-11 did not been affected by siRNAs transfection (Fig. 4B). Moreover, after transfected with siRNAs, the cells viability did not reveal a significantly difference, at least within 48 hours (Fig. $4 \mathrm{C}$; $\mathrm{P}>0.05)$. In the transwell assay, neither BSA nor the NC siRNAs showed any influence on AGS cell migration (Fig. 4D; Fig. 4E; Fig. 3A).
A

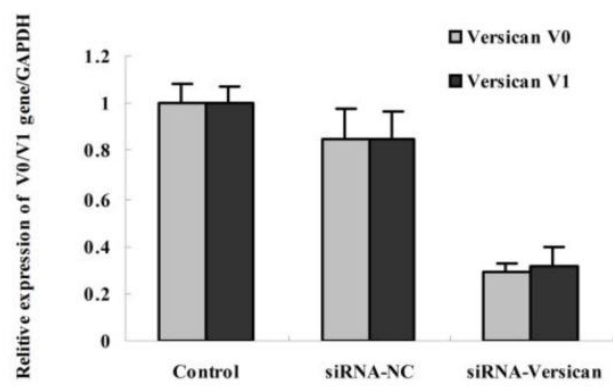

$\mathrm{C}$

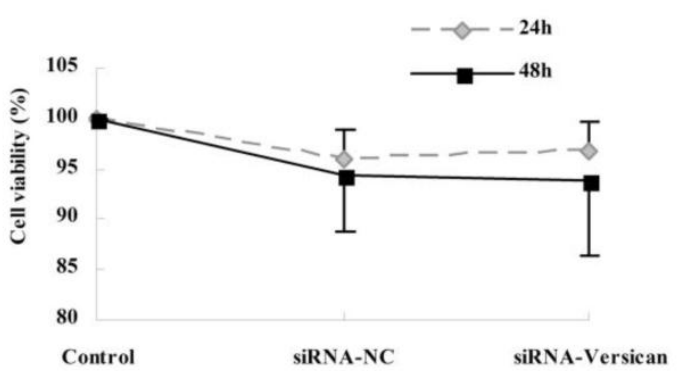

B

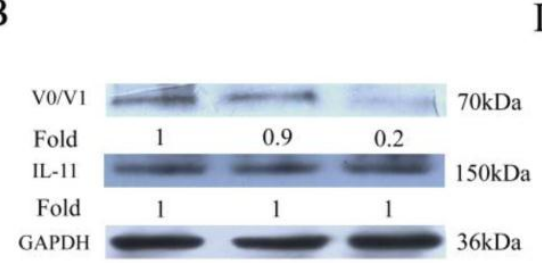

D
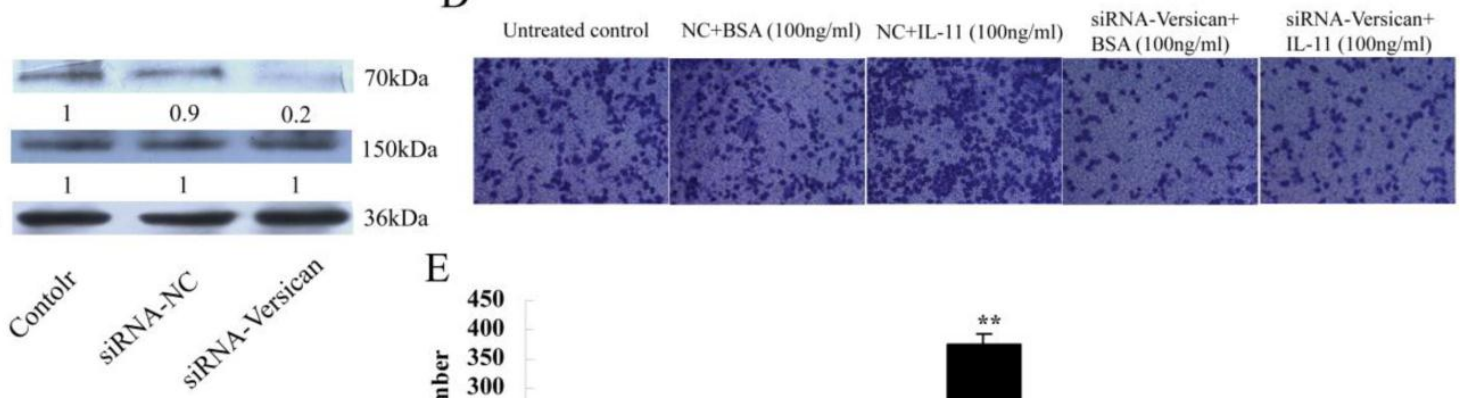

$\mathrm{E}$

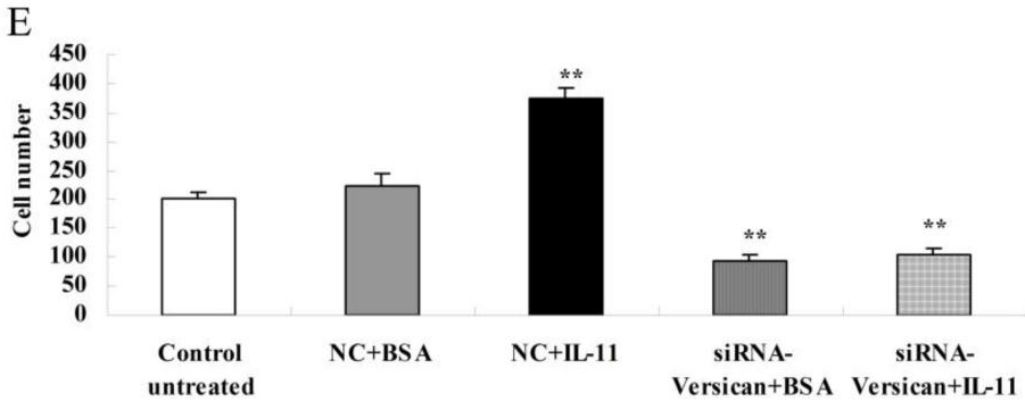

Fig 4. (A): Q-RT-PCR was performed to validate versican $V 0$ and $V I$ inhibition after $A G S$ cells were transfected with siRNA-versican. (B) Western blot analysis of versican VO/VI and IL-II protein levels. The results in (A) and (B) showed that versican V0/VI were significantly inhibited by siRNA-VO/VI but not by the negative control siRNA in AGS cells, and the expression of endogenous IL-II in cells was not affected by both siRNAs. (C) The cell viability of siRNAs transfected was measured by CCK- 8 assay. In both 24 and $48 \mathrm{~h}$ time points, the cell viability didn't show a significantly difference between siRNAs treated and untreated control groups $(P>0.05)$. (D) The effect of versican on AGS cell migration mediated by rhIL-I I was analysed in a transwell assay as described in the methods section. rhIL-I I-treated cells showed significantly higher migration rates $(* * P<0.01)$. siRNA-versican was able to decrease migration, both with and without rhIL-I I, compared to the untreated control and BSA $(* * P<0.0 I)$. (E) The migrated cells were quantified and expressed as the mean \pm SD of three independent experiments. 
Additionally, after being transfected with NC siRNAs, the cells revealed a significantly higher migration rate in the presence of rhIL-11 $(100 \mathrm{ng} / \mathrm{ml})$ compared to untreated controls (Fig. 4D; Fig. 4E; $\mathrm{P}<0.01$ ). However, following treatment with siRNA-versican, the enhanced migration of the cells by rhIL-11 was reversed. When IL-11 $(100 \mathrm{ng} / \mathrm{ml})$ was added, the migration of the siRNA-versican-treated cells decreased relative to the untreated control (Fig. 4D; Fig. 4E; $P<0.01$ ).

Collectively, these results led the authors to conclude that both versican and IL-11 play an important role in regulating the migration of malignant gastric cells, and versican, together with IL-11, participates in the regulation of gastric cell migration.

\section{Discussion}

In the present study, our results agree well with previous reports of significantly elevated versican expression in human gastric carcinomas relative to the adjacent normal gastric mucosa[20-22]. Versican mediates cell-ECM interaction and the stable expression of it enhances cell attachment and the expression of $\beta 1$ integrin and fibronectin[34]. It has been suggested that the abnormal expression of versican is related to cell proliferation, differentiation, adhesion, and even the homeostasis and integrity of the ECM[5]. The up-regulated versican, interacting with its partners, modulate the organization of the ECM and promote tumor growth[9, 24]. While versican V0/V1 silencing has been suggested to cause a decrease in cell proliferation and migration, both in wound healing assays and in transwell chambers[35]. So, the elevated versican may be obligatory for angiogenesis and metastasis in tumours[19]. Metastasis is the most critical aspect of tumourigenesis, and more than $90 \%$ of cancer mortality is caused by metastasis[36]. Recent studies unambiguously show that the extracellular matrix component versican, which activates macrophages through Toll-like receptor (TLR) 2 and its co-receptors TLR6 and CD14, strongly enhances Lewis lung cell carcinoma metastasis[33]. Thus, to some extent, one can say that versican is a metastasis-enhancing factor.

The four identified versican isoforms and their differential expression have been observed in multiple human cancers. It has been suggested that all four isoforms were significantly overexpressed in human breast cancer[37]. Additionally, higher steady-state levels of mRNA transcripts and gene products of the versican variants $\mathrm{V} 0, \mathrm{~V} 1$, and $\mathrm{V} 3$ were detected in the nodular tissues than in the non-nodular parenchyma of benign prostatic hyperplasia[38]. The differential expression of specific isoforms may be involved in and even influence tumour cell behaviour[39, 40]. For instance, all melanoma cell lines with an early or intermediate degree of differentiation expressed $\mathrm{V} 0$ and V1 isoforms, whereas V2 and V3 expression were observed only in undifferentiated cell lines[41]. Syrokou et al. have proved that the synthesis and expression of mRNA encoding for different versican splice variants were related to the aggregation of human epithelial mesothelioma cells[42]. In our present work, the differential expression of versican isoforms was detected for the first time, and V0 and V1 were found to be the predominant isoforms present in gastric samples as well as some gastric carcinoma cell lines. Our findings, which were consistent with previous reports, suggested that the differential expression of specific isoforms may participate in the progression of gastric carcinoma.

Next, we showed that the exogenous IL-11 alone could increase the migration and proliferation of the gastric carcinoma cell lines. This corresponds to previous data that IL-11 acts as a cell mitogen and upregulates the invasive activity of human gastric carcinoma cells[27, 29]. Through proangiogenic and pro-proliferative mechanisms, IL-11 has been implicated in gastric restitution[43, 44]. Merchant suggested that IL-11, via Stat3, promotes inflammation-associated gastric tumourigenesis[45]. Additionally, Ernst et al. also reinforced the critical importance of the IL-11/Stat3 signal transduction pathway in gastric tumours in mice[32]. IL-11 and versican have been individually implicated in tumour progression[20, 21, 29], but their potential regulations or interactions under these conditions have not been considered. Thus, the knowledge that these two species are regulated or mediated by each other may further our understanding of their functions in cancer.

Interestingly, in our research, we demonstrated that exogenous IL-11 could directly affect the expression of the versican variants both in the AGS and MKN45 cell lines, favouring the GAG-rich variants. Furthermore, the expression of versican V0/V1 was markedly inhibited by siRNA-versican, and the enhanced migration of the cells by IL-11 was reversed. Perhaps the most intriguing question that needs further investigation is how versican expression is regulated by exogenous IL-11. IL-11 could regulate epithelial cell turnover by STAT3 and ERK1/2 dependent pathway[29]. And versican interacts with EGFR through its C-terminal globular domains[9]. In addition, treatment with rhIL-11 stimulated expression of several MMPs (Matrix Metallo Proteinases) in stomachs of wild-type mice[46]. While MMP types $-1,-2,-3,-7$, and -9 , have also been shown to cleave versican in vitro[47, 48]. So, by bridge of STAT3 and ERK1/2 
signalling or MMPs, IL-11 may regulate the synthesis of versican, at least partly. Nevertheless, on the basis of the achieved results, one can propose that the IL-11-induced migration change was, to some extent, a result of elevated versican.

These results not only support the proposed role of versican as a proliferative and pro-migratory molecule, but also prove that IL-11 triggers the malignant phenotype of gastric carcinoma cells by the induction of migration and that this effect is mediated by versican V0/V1. Thus, our research, which is consistent with previous studies, demonstrates that IL-11 can regulate the expression of versican and its variants in gastric cell lines, and versican, together with IL-11, participates in the regulation of gastric cell migration. Alternatively, our results suggest that some growth factors or cytokines that act as important mediators of inflammation might exert their effects first on the extracellular matrix components, such as versican, to create a hostile microenvironment for tumour progression or subsequent steps of inflammation. The identification of the nature of the interaction of versican with these and other inflammatory mediators awaits further study.

In conclusion, our study demonstrates, for the first time, the differential expression of versican variants in gastric samples as well as some gastric carcinoma cell lines and the alterations in the mRNA patterns of V0 and V1 isoforms when cells are treated with rhIL-11. IL-11 promotes the malignant phenotype of gastric carcinomas by the induction of migration, and this effect is, at least in part, mediated by versican $\mathrm{V} 0 / \mathrm{V} 1$.

\section{Conflict of Interests}

The authors have declared that no conflict of interest exists.

\section{References}

1. Oue N, Sentani K, Sakamoto N, et al. Characteristic gene expression in stromal cells of gastric cancers among atomic-bomb survivors. Int J Cancer. 2009; 124: 1112-21.

2. Hartgrink HH, Jansen EP, van Grieken NC, et al. Gastric cancer. Lancet. 2009; 374: 477-90.

3. Ricciardelli $\mathrm{C}$ and Rodgers RJ: Extracellular matrix of ovarian tumors. Semin Reprod Med 2006; 24: 270-82.

4. Ricciardelli C, Sakko AJ, Ween MP, et al. The biological role and regulation of versican levels in cancer. Cancer Metastasis Rev. 2009; 28: 233-45.

5. Wight TN. Versican: a versatile extracellular matrix proteoglycan in cell biology. Curr Opin Cell Biol. 2002; 14: 617-23.

6. Zako M, Shinomura T, Ujita M, et al. Expression of PG-M (V3), an alternatively spliced form of PG-M without a chondroitin sulfate attachment in region in mouse and human tissues. J Biol Chem. 1995; 270: 3914-8.

7. Landolt RM, Vaughan L, Winterhalter $\mathrm{KH}$, et al. Versican is selectively expressed in embryonic tissues that act as barriers to neural crest cell migration and axon outgrowth. Development 1995; 121: 2303-12.

8. Schmalfeldt M, Dours-Zimmermann MT, Winterhalter KH. Versican V2 is a major extracellular matrix component of the mature bovine brain. J Biol Chem. 1998; 273: 15758-64.

9. Wu YJ, La Pierre DP, Wu J, et al. The interaction of versican with its binding partners. Cell Res. 2005; 15: 483-94.

10. LeBaron RG, Zimmermann DR, Ruoslahti E. Hyaluronate binding properties of versican. J Biol Chem. 1992; 267:10003-10.

11. Aspberg A, Binkert C, Ruoslahti E. The versican C-type lectin domain recognizes the adhesion protein tenascin-R. Proc Natl Acad Sci U S A. 1995; 92: 10590-4.

12. Aspberg A, Adam S, Kostka G, et al. Fibulin-1 is a ligand for the C-type lectin domains of aggrecan and versican. J Biol Chem. 1999; 274: 20444-9.

13. Isogai Z, Aspberg A, Keene DR, et al. Versican interacts with fibrillin-1 and links extracellular microfibrils to other connective tissue networks. J Biol Chem. 2002; 277: 4565-72.

14. Yamagata M, Yamada KM, Yoneda M, et al. Chondroitin sulfate proteoglycan (PG-M-like proteoglycan) is involved in the binding of hyaluronic acid to cellular fibronectin. J Biol Chem. 1986;261:13526-35.

15. Kawashima $\mathrm{H}$, Hirose $\mathrm{M}$, Hirose J, et al. Binding of a large chondroitin sulfate/dermatan sulfate proteoglycan, versican,to L-selectin, P-selectin, and CD44. J Biol Chem. 2000; 275: 35448-56.

16. Wu Y, Chen L, Zheng PS, et al. beta 1-Integrin-mediated glioma cell adhesion and free radical-induced apoptosis are regulated by binding to a C-terminal domain of PG-M/versican. J Biol Chem. 2002; 277: 12294-301.

17. Evanko SP, Angello JC, Wight TN. Formation of hyaluronanand versican-rich pericellular matrix is required for proliferation and migration of vascular smooth muscle cells. Arterioscler Thromb Vasc Biol. 1999; 19: 1004-13.

18. Choocheep K, Hatano S, Takagi H, et al. Versican facilitates chondrocyte differentiation and regulates joint morphogenesis. J Biol Chem. 2010; 285: 21114-25.

19. Yang BL, Zhang Y, Cao L, et al. Cell adhesion and proliferation mediated through the G1 domain of versican. J Cell Biochem. 1999; 72: 210-20.

20. Setoguchi T, Kikuchi H, Yamamoto M, et al. Microarray analysis identifies versican and CD9 as potent prognostic markers in gastric gastrointestinal stromal tumors. Cancer Sci. 2011; 102: 883-9.

21. Theocharis AD, Vynios $\mathrm{DH}$, Papageorgakopoulou $\mathrm{N}$, et al. Altered content composition and structure of glycosaminoglycans and proteoglycans in gastric carcinoma. Int J Biochem Cell Biol. 2003; 35: 376-90.

22. Ju H, Lim B, Kim M, et al. Genetic variants A1826H and D2937Y in GAG-beta domain of versican influence susceptibility to intestinal-type gastric cancer. J Cancer Res Clin Oncol. 2010; 136: 195-201.

23. Berdiaki A, Zafiropoulos A, Fthenou E, et al. Regulation of hyaluronan and versican deposition by growth factors in fibrosarcoma cell lines. Biochimica Biophysica Acta. 2008; 1780: 194-202.

24. Norian JM, Malik M, Parker CY, et al. Transforming growth factor beta3 regulates the versican variants in the extracellular matrix-rich uterine leiomyomas. Reprod Sci. 2009; 16:1153-64.

25. Lemire JM, Chan CK, Bressler S, et al. Interleukin-1beta selectively decreases the synthesis of versican by arterial smooth muscle cells. J Cell Biochem. 2007; 101: 753-66.

26. Du X, Williams DA. Interleukin-11: review of molecular, cell biology, and clinical use. Blood. 1997; 89: 3897-908.

27. Nakayama T, Yoshizaki A, Izumida $S$, et al. Expression of interluekin-11 (IL-11) and IL-11 receptor alpha in human gastric 
carcinoma and IL-11 upregulates the invasive activity of human gastric carcinoma cells. Int J Oncol. 2007; 30: 825-33.

28. Reddy KB, Nabha SM, Atanaskova N. Role of MAP kinase in tumor progression and invasion. Cancer Metastasis Rev. 2003; 22: 395-403.

29. Jackson CB, Judd LM, Menheniott TR, et al. Augmented gp130-mediated cytokine signaling accompanies human gastric cancer progression. J Pathol. 2007; 213: 140-51.

30. Huang C, Rajfur Z, Yousefi N, et al. Talin phosphorylation by Cdk5 regulates Smurf1-mediated talin head ubiquitylation and cell migration. Nat Cell Biol. 2009; 11: 624-30.

31. Zhang K, Yao HP, Wang MH. Activation of RON differentially regulates claudin expression and localization: role of claudin-1 in RON-mediated epithelial cell motility. Carcinogenesis. 2008; 29: 552-9.

32. Ernst M, Najdovska M, Grail D, et al. STAT3 and STAT1 mediate IL-11-dependent and inflammation-associated gastric tumorigenesis in gp130 receptor mutant mice. J Clin Invest. 2008;118:1727-38.

33. Kim S, Takahashi H, Lin WW, et al. Carcinoma-produced factors activate myeloid cells through TLR2 to stimulate metastasis. Nature. 2009; 457: 102-6.

34. Wu YJ, Wu J, Lee DY, et al. Versican protects cells from oxidative stress-induced apoptosis. Matrix Biology 2005; 24: 3-13.

35. Hernández D, Miquel-Serra L, Docampo MJ, et al. Role of versican V0/V1 and CD44 in the regulation of human melanoma cell behavior. Int J Mol Med. 2011; 27: 269-75.

36. Grivennikov SI, Greten FR, Karin M. Immunity, Inflammation, and Cancer. Cell 2010; 140: 883-99.

37. Kischel P, Waltregny D, Dumont B, et al. Versican overexpression in human breast cancer lesions: known and new isoforms for stromal tumor targeting. Int J Cancer. 2010, 126: 640-50.

38. True LD, Hawley S, Norwood TH, et al. The accumulation of versican in the nodules of benign prostatic hyperplasia. Prostate. 2009; 69: 149-58.

39. Lemire JM, Merrilees MJ, Braun KR, et al. Overexpression of the V3 variant of versican alters arterial smooth muscle cell adhesion, migration, and proliferation in vitro. J Cell Physiol. 2002; 190: 38-45.

40. Miquel-Serra L, Serra M, Hernandez D, et al. V3 versican isoform expression has a dual role in human melanoma tumor growth and metastasis. Lab Invest. 2006; 86: 889-901.

41. Domenzain C, Docampo MJ, Serra M, et al. Differential expression of versican isoforms is a component of the human melanoma cell differentiation process. Biochim Biophys Acta. 2003; 1642: 107-14.

42. Syrokou A, Dobra K., Tzanakakis GN, et al. Synthesis and expression of mRNA encoding for different versican splice variants is related to the aggregation of human epithelial mesothelioma cells. Anticancer Res. 2002; 22:4157-62.

43. Wen CY, Ito M, Wang H, et al. IL-11 up-regulates Tie-2 expression during the healing of gastric ulcers in rats. World J Gastroenterol. 2003; 9: 788-90.

44. Wen CY, Ito M, Matsuu M, et al. Mechanism of the antiulcerogenic effect of IL-11 on acetic acid-induced gastric ulcer in rats. Life Sci. 2002; 70: 2997-3005.

45. Merchant JL. What lurks beneath: IL-11, via Stat3, promotes inflammation-associated gastric tumorigenesis. J Clin Invest. 2008; 118: 1628-31.

46. Howlett M, Judd LM, Jenkins B, et al. Differential regulation of gastric tumor growth by cytokines that signal exclusively through the coreceptor gp130. Gastroenterology. 2005; 129: 1005-18.

47. Perides G, Asher RA, Lark MW, et al. Glial hyaluronate-binding protein: a product of metalloproteinase digestion of versican? Biochem J. 1995; 312 ( Pt 2): 377-84.
48. Passi A, Negrini D, Albertini R, et al. The sensitivity of versican from rabbit lung to gelatinase A (MMP-2) and B (MMP-9) and its involvement in the development of hydraulic lung edema. FEBS Lett. 1999; 456: 93-6. 